\title{
Analisis Gaya Bahasa Perulangan pada Lirik Lagu dalam Album Monokrom Karya Tulus dan Implikasinya Terhadap Pembelajaran Bahasa Indonesia di SMA
}

\author{
Oleh: \\ Rina Rosdiana ${ }^{1}$, Ega Septiani Putri² \\ 1, Pendidikan Bahasa dan Sastra Indonesia, FKIP UNPAK, Bogor \\ 2, Pendidikan Bahasa dan Sastra Indonesia, FKIP UNPAK, Bogor
}

\begin{abstract}
Language is very close to human life because language is able to convey a message through spoken words, especially in song lyrics that have the same characteristics as poetry, this is certainly contains a diverse language style. This study aims to find out the use of language styles on song lyrics in a monochrome album of Tulus. Not only about that, this also aims to know the implications of using language styles in learning Indonesian in Senior high school. The writer uses qualitative descriptive method in this research techniques that refers to the theories of the experts. The research data used in conducting the research is to use excerpts the lyrics of song containing repetitive language styles such as simploke, chiasm, epizeukis and anaphora. Moreover, the data that has been collected will be analyzed and described. The result of the language styles analysis in the lyrics of the song are found 68 quotes, including simploke 13, chiasmus 39, epizeukis 6 , and anafora 8 . The results of this study can be used as teaching material innovation in Indonesian language learning in senior high school because the language styles materials are learned by the senior high school students. The use of repetitive language styles has an important connection to suppressing meaning, so students are able to express their message. However, from 10 songs on the monochrome album, it can be concluded that the song has more chiasm. Chiasm is a style of language in which there are two different words but it can have the same or different meaning.
\end{abstract}

Keywords: The Repetition of Language Style Simploke, Chiasmus, Epizeukis, Anafora, Song Lyrics.

\begin{abstract}
ABSTRAK
Bahasa sangat erat sekali dengan kehidupan manusia. Melalui bahasa, manusia menyampaikan pesan dan perasaan. Salah satu bentuk pengungkapan perasaan adalah melalui lirik lagu. Penelitian ini bertujuan untuk mengetahui penggunaan gaya bahasa pada lirik lagu dalam album monokrom karya Tulus dan mengetahui implikasi penggunaan gaya bahasa dalam pembelajaran bahasa Indonesia di SMA. Metode yang digunakan dalam penelitian ini adalah metode deskriptif kualitatif. Teknik yang digunakan dalam penelitian ini teknik studi pustaka. Data peneliti berupa kutipan lirik lagu yang mengandung gaya bahasa perulangan (simploke, kiasmus, epizeukis, anafora), kemudian dianalisis dan dideskripsikan. Hasil analisis gaya bahasa pada lirik lagu ditemukan 68 kutipan, diantaranya kutipan yang mengandung gaya bahasa simploke 13 , kiasmus 39 , epizeukis 6 , anafora 8 . Hasil penelitian ini dapat dijadikan sebagai inovasi bahan ajar pada pembelajaran Bahasa Indonesia di SMA karena adanya pembelajaran tentang gaya bahasa. Penggunaan gaya bahasa perulangan memiliki kaitan penting pada penekanan makna, sehingga peserta didik mampu mengutarakan pesannya. Dari 10 lagu yang ada di dalam album monokrom dapat disimpulkan bahwa lebih banyak penggunaan gaya bahasa kiasmus. Hal ini dikarenakan pengarang ingin menyampaikan pesan melalui dua hal yang berbeda namun dapat menghadirkan kesamaan dan perbedaan makna. Kiasmus sendiri merupakan gaya bahasa yang di dalamnya terkandung dua kata yang berbeda namun dapat memiliki makna yang sama atau berlainan.
\end{abstract}

Kata Kunci: Gaya Bahasa Perulangan Simploke, Kiasmus, Epizeukis, Anafora, Lirik Lagu. 



\section{PENDAHULUAN}

Bahasa merupakan alat komunikasi yang membantu manusia untuk menyampaikan sebuah pesan kepada yang lainnya. Bahasa sangat dekat sekali dengan kehidupan manusia karena bahasalah yang mampu menjadikan sebuah pesan tersampaikan melalui kata-kata yang terucap. Kemampuan bahasa sendiri dibagi menjadi empat keterampilan, menyimak, berbicara, membaca, menulis. Penyampaian bahasa sendiri dibagi menjadi dua, yaitu melalui lisan dan tulisan. Keduanya memiliki karakteristik yang berbeda, dari garis besarnya saja bisa dibedakan dari cara penyampaian.

Bahasa sendiri tidak lepas dari gaya bahasa yang memberikan sebuah penekanan atau sebuah rangkaian kata yang dapat didengar lebih bermakna. Menurut beberapa ahli gaya bahasa sendiri terdiri dari empat jenis gaya bahasa, gaya bahasa perbandingan, gaya bahasa pertentangan, gaya bahasa perulangan, dan gaya bahasa pertautan.

Gaya bahasa perbandingan terdiri dari perumpamaan, metafora, personifikasi, depersonifikasi, alegori, antitesis, pleonasme dan tautologi, periphrasis, antisipasi, epanortosis. Gaya bahasa pertentangan terdiri dari hiperbola, litotes, ironi, oksimoron, paronomasia, paralepsis, zeugma dan silepsis, satire, inuendo, antifrasis, paradoks, klimaks, antiklimaks, apostrof, anastrof, apofasis, hysteron proteron, hipalase, sinisme, sarkasme. Gaya bahasa perulangan terdiri dari aliterasi, asonansi, antanaklasis, kiasmus, epizeukis, tautotes, anafora, epistrofa, simploke, mesodilopsis, epanalepsis, anadiplosis.

Gaya bahasa pertautan terdiri dari metonimia, sinekdoke, eufemisme, ellipsis, inversi, dan gradasi. Dalam penelitian ini, peneliti hanya memfokuskan pada satu gaya bahasa yang ada, yaitu gaya bahasa perulangan, terdiri dari simploke, kiasmus, epizeukis, dan anaphora. Di dalam sebuah karya sastra, khususnya puisi, gaya bahasa perulangan sering kali terlihat sebagai pesan yang ingin disampaikan penulis bagi pembacanya. Adanya sebuah penekanan pada sebuah makna melalui pengulangan kata yang menjadikan gaya bahasa perulangan selalu dijumpai di sebuah karya sastra. Semua manusia membutuhkan bahasa dalam menyampaikan sebuah makna, terlebih lagi seorang penyanyi.

Penyanyi menyampaikan maknanya melalui bahasa yang dirangkai menjadi sebuah lirik lagu. Tidak jarang gaya bahasa yang mereka gunakan mengandung gaya bahasa yang melebih-lebihkan, adanya unsur penekanan, perbandingan, penggunaan majas, dan mengiaskan sebuah kalimat agar pendengarnya mampu menikmati permainan kata-kata yang dibalut dengan nada.

Di dalam sebuah lirik lagu perlu adanya gaya bahasa yang menjadikannya memiliki ciri khas bagi pendengar. Selain itu, gaya bahasa pula yang menjadikan sebuah lirik lagu kaya akan permainan kata-kata sehingga menimbulkan keindahan.

Mendengarkan lagu memang merupakan kegiatan yang mengasyikan karena akan membawa sensasi santai bagi si pendengar. Di dalam kelas, seorang peserta didik akan merasa tertarik bila pembelajaran yang dikemas menggunakan lirik lagu. Peserta didik akan merasa senang karena pembelajarannya dekat dengan kehidupannya sehari-hari, yaitu lagu. Tidak dapat dipungkiri lagu merupakan hal yang begitu dekat dengan kehidupan manusia saat ini, terkhusus bagi kehidupan anak sma. Maka dari itu lirik lagu merupakan hal 
yang tepat apabila dijadikan sebuah objek pembelajaran.

Lirik lagu sendiri memiliki kaitan dengan puisi. Mereka memiliki karakteristik yang sama yaitu sebuah bait yang terdiri dari kata-kata. Pembelajaran sastra yang menyenangkan akan tersampaikan apabila lirik lagu disampaikan di dalam pembelajaran. Salah satu penyanyi yang ada di Indonesia ialah Muhamad Tulus atau biasa dikenal dengan sebutan Tulus. Di dalam albumnya yang berjudul Monokrom terdapat banyak sekali gaya bahasa yang digunakan, salah satunya gaya bahasa perulangan. Penulis pun menjadikan latar belakang ini menjadi sebuah judul penelitian "Analisis Gaya Bahasa Perulangan pada Lirik Lagu dalam Album Monokrom Karya Tulus dan Implikasinya Terhadap Pembelajaran Bahasa Indonesia di SMA"

\section{TINJAUAN TEORETIS}

\section{Pengertian Gaya Bahasa}

Gaya bahasa merupakan sebuah gaya yang digunakan seseorang dalam menyampaikan gagasan kepada orang lain agar orang lain terkesan pada apa yang disampaikan. Gaya bahasa juga bisa dikatakan sebuah majas atau sebuah kata kiasan yang dapat menimbulkan rasa tersendiri bagi pembaca atau pendengar. Dengan menggunakan gaya bahasa, maka seseorang akan mudah menyampaikan apa yang ingin disampaikan.

Menurut Gorys Keraf gaya bahasa dapat mencerminkan kepribadian seseorang. Hal itu dapat terlihat dari gayanya seseorang dalam memilih sebuah kata. Semakin gaya bahasa yang digunakan baik, maka citra orang tersebut akan baik. Jika gaya bahasanya buruk, maka seseorang akan mencerminkan kepribadian yang buruk. Hal itu disebabkan karena gaya bahasa merupakan style atau ciri khas dari pemakai gaya bahasa tersebut. (Keraf, 2009: 113)

Hal itu menunjukkan bahwa gaya bahasa merupakan komponen penting bagi seorang penulis untuk memberi sebuah ciri khas terhadap tulisannya. Jika hal tersebut dilakukan maka hasil tulisannya dapat dikenali oleh orang lain dan memiliki ciri khas tersendiri. Hal tersebut menunjukkan bahwa gaya bahasa mampu memengaruhi penyimak atau pembaca dalam sebuah penyampaian pesan atau gagasan. Hasil karya sastra pasti memiliki sebuah pesan terselubung yang ingin disampaikan, maka gaya bahasa menjadi sebuah pondasi untuk menuliskan kata-kata. (Tarigan, 2009:4)

Menurut Finoza (2008 : 135) Gaya bahasa atau langgam bahasa dan sering juga disebut majas adalah cara penutur mengungkapkan maksudnya. Banyak cara yang dapat dipakai untuk mengungkapkan maksud. Ada cara yang memakai perlambang (majas metafora, personifikasi) ; ada cara yang menekankan kehalusan (majas eufemisme, litotes); dan masih banyak lagi majas yang lainnya. Semua itu pada prinsipnya merupakan corak seni berbahasa atau retorika untuk menimbulkan kesan tertentu bagi mitra komunikasi.

Ini menunjukkan bahwa seseorang yang memainkan gaya bahasa memiliki segudang kata-kata di pikirannya sendiri. Menunjukkan bahwa bahasa sendiri memiliki kekayaan untuk menyampaikan pesan dengan efek-efek tertentu. Mampu menyampaikan sebuah ekspresi dari dalam dirinya melalui kata-kata yang bermakna.

Jadi gaya bahasa merupakan sebuah ciri khas atau gaya seseorang dalam menyampaikan sebuah pesan. Gaya bahasa sendiri dapat berguna sebagai keindahan seorang penyair atau penulis dalam karya seninya. 


\section{Macam-Macam Gaya Bahasa}

Guntur Tarigan menyatakan bahwa ada enam puluh gaya bahasa yang termasuk ke dalam empat kelompok, gaya bahasa perbandingan, gaya bahasa perulangan, gaya bahasa pertentangan, dan gaya bahasa pertautan. (Tarigan, $2009: 6$ )

Kemudian menurut Keraf (2009 : 115) gaya bahasa dapat ditinjau dari bermacammacam sudut pandangan. Oleh sebab itu, sulit diperoleh kata sepakat mengenai suatu pembagian yang bersifat menyeluruh dan dapat diterima oleh semua pihak. Pandangan-pandangan atau pendapatpendapat tentang gaya bahasa sejauh ini sekurang-kurangnya dapat dibedakan, pertama, dilihat dari segi non kebahasaan dan yang kedua ialah dari segi kebahasaannya.

Keraf (2009 : 115) membagi gaya bahasa dari segi bahasanya sendiri menjadi tujuh pokok, berdasarkan pengarang, berdasarkan masa, berdasarkan medium atau alat komunikasi, berdasarkan subyek, berdasarkan tempat, berdasarkan hadirin, dan berdasarkan tujuan. Gaya bahasa menurut segi kebahasaannya terdiri dari gaya bahasa berdasarkan pilihan kata, berdasarkan nada yang terkandung dalam wacana, berdasarkan struktur kalimat, dan berdasarkan langsung tidaknya makna.

\section{Teori Gaya Bahasa Perulangan}

1. Gaya Bahasa Simploke

Simploke atau bisa disebut symploche merupakan gaya bahasa repetisi pada awal dan akhir beberapa baris atau kalimat berturut-turut.

\section{Gaya Bahasa Kiasmus}

Kiasmus (chiasmus) adalah semacam acuan atau gaya bahasa yang terdiri dari dua bagian, baik frasa atau klausa, yang sifatnya berimbang, dan dipertentangkan satu sama lain, tetapi susunan frasa atau klausanya itu terbalik bila dibandingkan dengan frasa atau klausa lainnya. (Gorys Keraf, 2009:132)

\section{Gaya Bahasa Epizeukis}

Menurut Tarigan (2009 : 182) epizeukis adalah gaya bahasa perulangan yang bersifat langsung, yaitu kata yang ditekankan atau yang dipentingkan diulang beberapa kali berturut-turut.

4. Gaya Bahasa Anafora

Anafora adalah gaya bahasa repetisi yang berupa perulangan kata pertama pada setiap baris atau setiap kalimat. (Tarigan, 2009 : 184)

\section{Pengertian Lirik Lagu}

Lirik lagu adalah sebuah kata-kata yang menggambarkan perasaan atau hasil pikiran imajinasi pengarang. Dalam mengekspresikan pengalamannya, penyair atau pencipta lagu melakukan permainan kata-kata dan bahasa untuk menciptakan daya tarik dan kekhasan terhadap lirik atau syairnya.

\section{Perpaduan Lirik Lagu dan Puisi}

Kesamaan puisi dan lirik lagu terdapat pada unsur batin dan fisik yang terkandung di dalam sebuah puisi. Unsur batin puisi atau unsur makna puisi terdiri atas empat bagian yang tidak terpisahkan, yaitu tema, perasaan penyair, nada atau sikap penyair terhadap pembaca, amanat. (Waluyo, $1991: 180)$

\section{Tujuan Pembelajaran Gaya Bahasa dalam Mata Pelajaran Bahasa Indonesia}

Pembelajaran bahasa pun tak luput dari pembelajaran gaya bahasa, sebuah pembelajaran yang mengajarkan siswa memilih sebuah kata atau diksi untuk hasil karya yang dibuatnya. Siswa dapat 
mengekspresikan perasaannya melalui kata-kata. Gaya bahasa akan membangun kreativitas dan inovatif sesuai tujuan yang ada di dalam kurikulum.

\section{Kedudukan dan Fungsi Bahasa Indonesia}

Hasil perumusan seminar politik bahasa nasional yang diselenggarakan di Jakarta pada tanggal 25-28 Februari 1975 antara lain menegaskan bahwa dalam kedudukannya sebagai bahasa nasional, bahasa Indonesia berfungsi sebagai lambang kebanggaan nasional, lambang identitas nasional, alat pemersatu berbagai masyarakat yang berbeda-beda latar belakang sosial budaya dan bahasanya, dan alat perhubungan antar budaya antar daerah.

\section{Pembelajaran Gaya Bahasa pada Mata Pelajaran Bahasa Indonesia}

Pelajaran bahasa Indonesia tidak terlepas dari karya sastra yang ada. Seperti drama, prosa, dan puisi sangat berperan penting dalam proses pembelajaran bahasa Indonesia di sekolah. Sesuai dengan tujuan pembelajaran bahasa Indonesia yang bertujuan membuat siswa inovatif dan kreatif maka gaya bahasa harus dipelajari bagi siswa. Dengan gaya bahasa maka siswa akan diperkenalkan dengan kata-kata yang akan membangun pikiran imajinatifnya sehingga lahirnya sebuah karya yang membanggakan.

\section{Fungsi Pembelajaran Bahasa Indonesia}

Fungsi pembelajaran bahasa Indonesia adalah merupakan salah satu alat penting untuk mencapai tujuan Pendidikan Nasional, menanamkan, memupuk, dan mengembangkan perasaan satu nusa, satu bangsa, dan satu bahasa. Memupuk dan mengembangkan kecakapan berbahasa Indonesia lisan dan tulisan. Memupuk dan mengembangkan kecakapan berpikir dinamis, rasional, dan praktis. Memupuk dan mengembangkan keterampilan untuk memahami, mengungkapkan dan menikmati keindahan bahasa Indonesia secara lisan maupun tulisan (Depdikbud,1995/1996:2).

\section{Fungsi Pembelajaran Sastra}

Menurut (Oemarjati, 1992) pengajaran sastra pada dasarnya mengemban misi efektif, yaitu memperkaya pengalaman siswa dan menjadikannya lebih tanggap terhadap peristiwa-peristiwa di sekelilingnya. Tujuan akhirnya adalah menanam, menumbuhkan, dan mengembangkan kepekaan terhadap masalah-masalah manusiawi, pengenalan dan rasa hormatnya terhadap tata nilai, baik dalam konteks individual, maupun sosial.

\section{METODELOGI PENELTIAN}

Peneliti menggunakan metode kualitatif sebagai landasan dalam meneliti. Metode ini digunakan untuk menghasilkan penemuan-penemuan yang tidak dapat dicapai dengan menggunakan prosedurprosedur statistik atau cara lain dari kuantifikasi atau pengukuran (Sujarweni, 2014:19). Dalam penelitian ini data yang terkumpul berupa lirik-lirik lagu bukan merupakan angka. Kemudian data akan dianalisis sesuai gaya bahasa perulangan yang ada pada lirik lagu di album Monokrom karya Tulus.

\section{Data dan Sumber Data}

Data dalam penelitian ini yaitu kalimatkalimat yang terdapat di lirik lagu pada album Monokrom karya Muhamad Tulus yang mengandung gaya bahasa perulangan yaitu terdiri atas simploke, kiasmus, epizeukis, dan anafora. 
Sumber data yang digunakan dalam penelitian ini yaitu album lagu Monokrom karya Muhamad Tulus.

\section{Tahap-Tahap Penelitian}

1. Tahap Persiapan Pra-Lapangan

2. Tahap Pelaksanaan Penelitian

3. Tahap Penyelesaian

\section{PEMBAHASAN}

Berikut ini adalah temuan penelitian yang telah dianalisis, kemudian dimasukkan ke dalam tabel rekapitulasi data.

\begin{tabular}{|l|l|l|l|}
\hline GBS & GBK & GBE & GBA \\
Simploke & Kiasmus & Epizeukis & Anafora \\
\hline 13 & 39 & 5 & 11 \\
\hline
\end{tabular}

Di dalam album monokrom karya Tulus mengandung 68 gaya bahasa perulangan (simploke, kiasmus, epizeukis, dan anafora. Gaya bahasa Simploke terdiri dari 13, kiasmus 39, epizeukis 6, dan anafora 11. Peneliti melihat adanya kecenderungan gaya bahasa kiasmus di antara gaya bahasa lainnya. Ini menandakan adanya sebuah penekanan makna yang ingin disampaikan oleh Tulus melalui dua frasa atau kata yang berbeda namun disatukan di dalam sebuah kalimat.

\section{Implikasi dalam Pembelajaran Bahasa Indonesia di SMA}

Peserta didik akan diberikan pelajaran tentang gaya bahasa menggunakan bahan ajar yaitu lirik lagu. Khususnya pada lirik lagu yang ada di dalam album Monokrom karya Tulus. Di dalam album Monokrom banyak sekali terkandung gaya bahasa perulangan (simploke, kiasmus, epizeukis, dan anafora) yang nanti dapat dianalisis oleh peserta didik. Akan ada sebuah gaya pembelajaran yang baru, mereka akan mencari gaya bahasa pada lirik lagu yang didengarkan.

\section{SIMPULAN}

Setelah peneliti melakukan analisis gaya bahasa perulangan (simploke, kiasmus, epizeukis, anafora) pada lirik lagu di dalam album monokrom karya Tulus maka dapat diperoleh sebuah simpulan sebagai berikut.

1. Menggunakan gaya bahasa perulangan maka sebuah pesan dapat lebih ditekankan atau ditegaskan kepada pendengar atau pembaca karena adanya sebuah kata yang diulang.

2. Setiap gaya bahasa perulangan memiliki karakteristiknya masingmasing yang membuat permainan kata-kata semakin indah. Simploke merupakan rangkaian kata atau kalimat yang sama, terletak di awal dan akhir bait.

3. Sebenarnya tidak semua lirik lagu dapat dijadikan bahan ajar di dalam kelas, harus lebih teliti sebelum memilihnya. Pastikan banyak katakata yang bermakna, sehingga lirik lagu tersebut layak dijadikan sebuah pembelajaran di dalam kelas karena pada zaman sekarang banyak lagulagu yang kata-katanya menjerumus pada hal keburukan.

\section{SARAN}

Berdasarkan hasil penelitian, maka peneliti memiliki saran-saran untuk membangun atau memberi masukan yang positif bagi beberapa pihak.

1. Guru bahasa Indonesia di SMA harus selalu berinovasi mencari bahan ajar yang lingkupannya dekat 
dengan dunia anak, sehingga pembelajaran akan tersampaikan.

2. Sebagai seorang guru sebaiknya kita lebih memperluas wawasan diri tentang dunia kebahasaan dan kesusastraan agar peserta didik mendapatkan informasi yang banyak perihal dunia bahasa dan sastra.

3. Peserta didik lebih terbuka pandangannya tentang dunia sastra, memahami bahwa sebuah lirik lagu yang mereka dengarkan bisa jadi salah satu sumber pembelajaran gaya bahasa.

\section{DAFTAR PUSTAKA}

Emzir. 2015. Metodologi Penelitian Pendidikan Kuantitatif dan Kualitatif. Edisi yang Diperbarui. Cetakan 9. Jakarta: PT Raja Grafindo Persada.

Finoza, Lamuddin. 2008. Komposisi Bahasa Indonesia. Cetakan 151. Jakarta: Diksi.

http://hariannetral.com/2015/08/pengertian -puisi-dan-unsur-unsur-puisilengkap.html\# (Diakses pada 21 November 2018)

https://media.neliti.com/media/publications /55527-ID-pembelajaran-sastrasebagai-salah-satu-w.pdf (Diakses pada 21 November 2018)

http://www.sekolahdasar.net/2012/04/tujua n-dan-fungsi-pembelajaranbahasa.html. (Diakses pada tanggal 6 Juli 2018)

Keraf, Gorys. 2009. Diksi dan Gaya Bahasa. Edisi yang Diperbarui. Cetakan 21. Jakarta: PT Gramedia Pustaka Utama.
Kosasih, E. 2008. Apresiasi Sastra Indonesia. Jakarta: PT Perca.

Moleong, Lexy J. 2017. Metodologi Penelitian Kualitatif. Cetakan 36. Bandung: PT Remaja Rosdakarya. Redaksi Immortal. 2012. Kamus Pintar Pantun Puisi dan Majas. Cetakan 3.

Yogyakarta: Immortal Publisher.

Salad, Hamdy. 2015. Panduan Wacana dan Apresiasi Musikalisasi Puisi.

Yogyakarta: Pustaka Belajar.

Sj Prier Edmund, Karl. 2008. Sejarah Musik Jilid 1. Cetakan 7. Yogyakarta: Percetakan Rejeki.

Sujarweni, Wiratna. 2014. Metodologi Penelitian. Yogyakarta: Pustakabarupress

Tarigan, Guntur. 2009. Pengajaran Gaya Bahasa. Edisi Revisi. Bandung: Angkasa 